\title{
Morphometric Study of C1 Pedicle and Feasibility Evaluation of C1 Pedicle Screw Placement with a Novel Clinically Relevant Radiological Classification in an Indian Population
}

\author{
Abhishek Srivastava ${ }^{1}$, Rajat Mahajan ${ }^{2}$, Ankur Nanda ${ }^{2}$, Geetanjali Nanda ${ }^{3}$, Nirajana Mishra ${ }^{4}$, \\ Vijayant Kanagaraju ${ }^{5}$, Sahil Batra ${ }^{6}$, Harvinder Singh Chhabra ${ }^{2}$ \\ ${ }^{I}$ Department of Spine Services, Primus Hospital, Chanakyapuri, New Delhi, India \\ ${ }^{2}$ Department of Spine Services, Indian Spinal Injuries Center, Vasant Kunj, New Delhi, India \\ ${ }^{3}$ Department of Radiodiagnosis, Mahajan Imaging Center, New Delhi, India \\ ${ }^{4}$ Independent Researcher, New Delhi, India \\ ${ }^{5}$ Department of Orthopedics, NMC Hospital, DIP, Dubai, UAE \\ ${ }^{6}$ Department of Spine Services, Caremax Superspeciality Hospital, Jalandhar, India
}

Study Design: A retrospective computed tomography (CT)-based morphometric study of 84 C1pedicles in an Indian population focusing on critical morphometric dimensions vis-a-vis $\mathrm{C} 1$ pedicle screw placement

Purpose: To determine the feasibility of $\mathrm{C} 1$ pedicle screw placement in an Indian population and propose a novel classification system for the same.

Overview of Literature: At present, $\mathrm{C} 1$ pedicle screws are rarely used, and very few studies have focused on the feasibility of pedicle screw placement in terms of racial, gender, and ethnic variations in anatomical structures. There are no CT-based data on C1 pedicles that assess the feasibility of pedicle screw placement in the Indian population.

Methods: We measured C1 pedicle diameter on CT coronal scan images of 42 adult patients. Extramedullary height (EMH) and intramedullary height (IMH) were measured. We examined the differences between the right and left atlas pedicles and compared measures between males and females. These data were analyzed using significance tests. Based on the results, we propose a novel classification system, which we believe will help in determining the feasibility of $\mathrm{C} 1$ pedicle screw placement.

Results: Forty-two adult patients (84 pedicles) were examined. Average EMH and IMH were $4.48 \pm 0.91$ and $0.86 \pm 0.77$, respectively. Approximately, $32 \%$ of the $\mathrm{C} 1$ pedicles had bone thicknesses of $<4 \mathrm{~mm}, 49 \%$ had IMH of $<1 \mathrm{~mm}$, and $38 \%$ had no pedicles. The average thickness in women was $4.21 \pm 0.93 \mathrm{~mm}$, which was significantly thinner than that in men $(4.73 \pm 0.81 \mathrm{~mm}, p=0.004)$. Right and left pedicles were not significantly different.

Conclusions: Our data indicate that approximately one-third of the Indian population may not be suitable candidates for C1 pedicle screw placement. Caution should be exercised while placing type 1B and type 2 pedicles based on our proposed classification system.

Keywords: Atlas anatomy; Cervical fixation; Atlantoaxial fixation; Atlanto-occipital fixation; Cervical pedicle screws; Cervical posterior fixation

Received Dec 2, 2016; Revised Jan 14, 2017; Accepted Feb 13, 2017

Corresponding author: Sahil Batra

Indian Spinal Injuries Centre, Spine Services, Vasant Kunj, New Delhi 110070, India

Tel: +01142255356, Fax: +01126898810,E-mail: sahil.ortho.dhs@gmail.com 


\section{Introduction}

Posterior transarticular screws are widely used for rigid atlantoaxial fixation, with good results [1]. Nevertheless, because of anatomical limitations and technical difficulties, an alternative technique involving separate instrumentation in Atlas (C1) and Axis (C2) vertebra is increasingly being used. This technique was initially described by Goel and Laheri [2] in 1994 and further popularized by Harms and Melcher [3]. It involves placing lateral mass screws in $\mathrm{C} 1$ and pedicle/pars screws in $\mathrm{C} 2$ connected by a rod/plate. This is a versatile technique, although accessing the $\mathrm{C} 1$ lateral mass can be difficult because of excessive bleeding from the venous plexus surrounding the $\mathrm{C} 1-$ C2 joint $[3,4]$. There is also a possibility of internal carotid artery and hypoglossal nerve injuries due to bicortical screw placement $[5,6]$. To minimize these risks, an alternative technique is suggested. This technique by Resnick and Benzel [7] uses the $\mathrm{C} 1$ pedicle as an entry to access the lateral mass. Because the $\mathrm{C} 1$ pedicle is just below the vertebral artery groove on the $\mathrm{C} 1 \mathrm{arch}$, the dimensions of this area are the limiting factor in determining the feasibility and screw size [8].

Genetic and ethnic variations are characteristic of spinal structures, such as pedicles. These variations may require instrumental modification or render the technique unsuitable for use in some ethnic groups because of incompatible anatomic variations. Atlas morphometry is extensively studied and well-documented in the literature [9-13]. However, there are very few studies of $\mathrm{C} 1$ pedicle morphometry [14-16]. In spite of the fact that the Indian population constitutes one-sixth of the world's population, there have been no reports of computed tomography (CT)-based $\mathrm{C} 1$ pedicle morphometry in the literature till date. We conducted a morphometric study to examine potential pathways for $\mathrm{C} 1$ pedicle screw placement and determine the feasibility of the procedure in an Indian population. Despite apparently adequate anatomy for pedicle screw placement on preoperative imaging, it is sometimes difficult to place the screws. This is generally ascribed to variations in the intramedullary canal. We also classified $\mathrm{C} 1$ pedicles based on extramedullary height $(\mathrm{EMH})$ and intramedullary height (IMH). Such a classification system may help surgeons preoperatively determine the feasibility of the technique and choose alternative methods in difficult cases.

\section{Materials and Methods}

After receiving appropriate approvals including the Institutional Review Board approval (ISIC/RP/2014/004) of Institutional Ethics committee (IEC) registered under central drug standard control organisation (CDSCO) is the national regulatory body, 50 random adult volumetric cervical spine CT scans, with a minimum slice thickness of $<1 \mathrm{~mm}(0.5-1 \mathrm{~mm})$, were obtained from the database of a single center based in New Delhi, India. The raw volumetric axial images were taken and used for CT reconstructions in the sagittal and coronal planes, using software (RadiAnt DIACOM viewer 4.0.2, Medixant, Poznan, Poland). Patients within complete cervical scans were excluded from the study. Patients with demonstrable atlas lesions in the form of fractures, tumors, infection, inflammatory disease, or congenital malformation were also excluded. Because the craniocaudal height of the atlas pedicle is the restrictive factor in pedicle screw placement $[14,15]$, we measured EMH and IMH (Figs. 1, 2). These measurements were performed from coronal reconstructions, as described by Gebauer et al. [17], using the bone window setting of the Picture Archiving and Communication System (PACS) software. EMH and IMH were determined at the thinnest portion located underneath the vertebral artery groove. All EMH and IMH measures were agreed upon by two authors based on the criteria by Gebauer et al. [17].

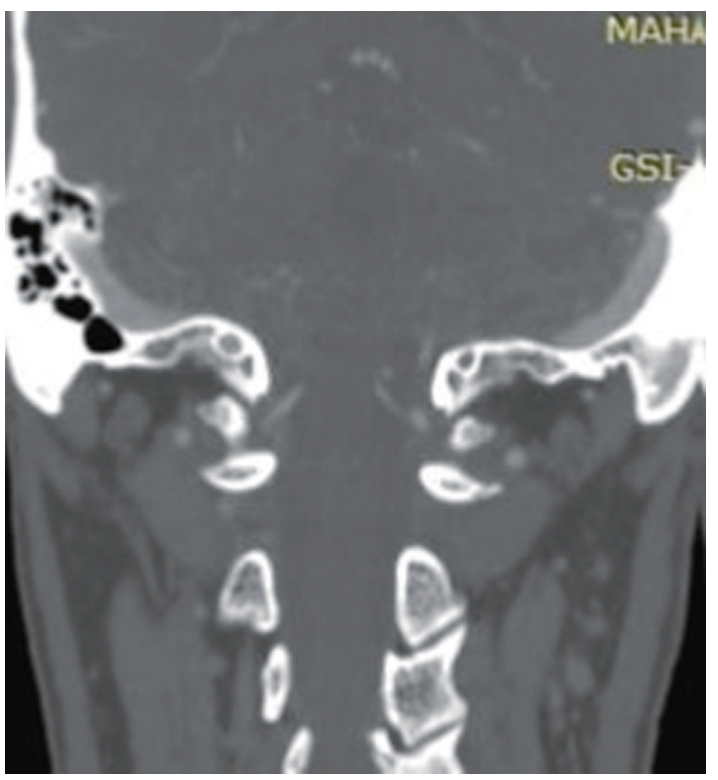

Fig. 1. A representative coronal computed tomography scan section depicting the $\mathrm{C} 1$ pedicle. 


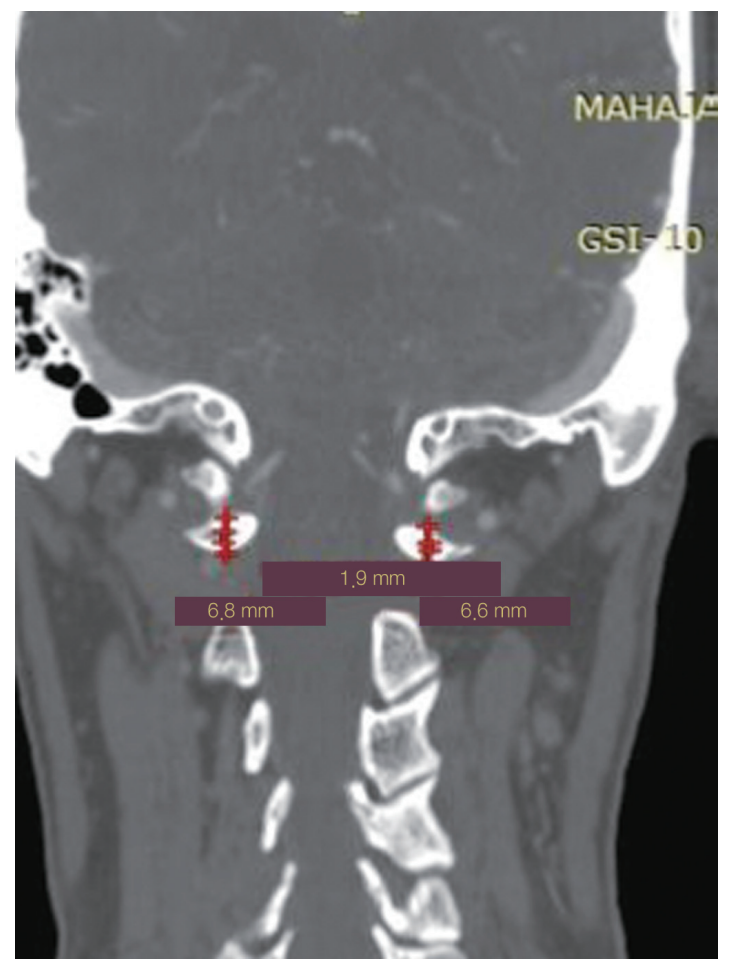

Fig. 2. Representative scans with intramedullary height and extramedullary height measurements of both positions.

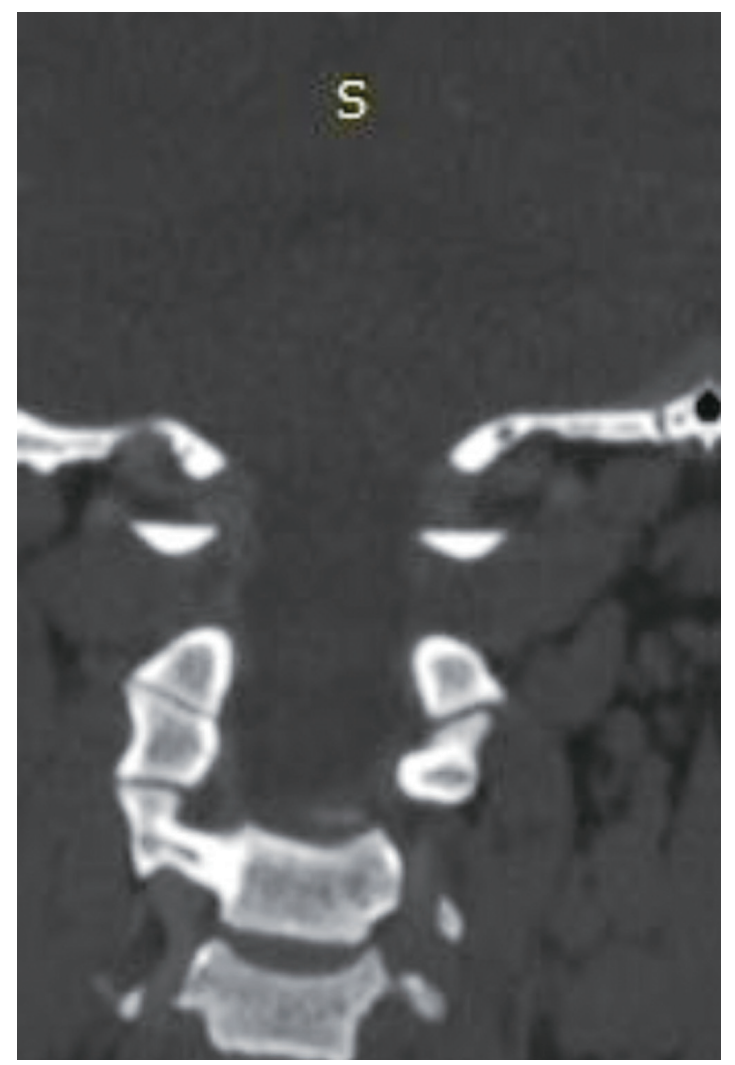

Fig. 3. A representative scan depicting C1 pedicles without any intramedullary canal.

Significance was calculated between right and left pedicle dimensions, along with gender variations, using the Student's $t$-test. EMH and IMH correlations were also determined. In addition, we aimed to distinguish the morphological patterns and thereby the feasibility to use instrumentation as per the morphology. This classification system, based on EMH and IMH, may assist physicians in preoperatively determining the feasibility of the procedure.

\section{Results}

Among the 50 randomly selected scans, one was of a pediatric patient (because of a clerical error) and seven were incomplete studies; hence, these were excluded. The final study sample consisted of 42 patients, with a total of 84 $\mathrm{C} 1$ pedicles. There were 21 males (age [mean \pm standard deviation, SD], $48.95 \pm 14.31$ years) and 21 females (average age [mean \pm SD], $47.29 \pm 13.59$ years). The left and right

Table 1. Author's radiological classification of $\mathrm{C} 1$ pedicles

\begin{tabular}{ll} 
Type & \multicolumn{1}{c}{ Classfication } \\
Type 1 & $\mathrm{EMH}>4 \mathrm{~mm}, \mathrm{IMH}>1 \mathrm{~mm}$ (pedicle screw: high feasibility) \\
& $\mathrm{EMH}>4 \mathrm{~mm}, \mathrm{IMH}<1 \mathrm{~mm}$ (pedicle screw with caution) \\
\hline Type 2 & $\mathrm{EMH}>4 \mathrm{~mm}, \mathrm{no} \mathrm{IMH}$ (extreme caution) \\
Type 3 & $\mathrm{EMH}<4 \mathrm{~mm}$ (not advisable) \\
\hline
\end{tabular}

$\mathrm{EMH}$, extramedullary height; IMH, intramedullary height.

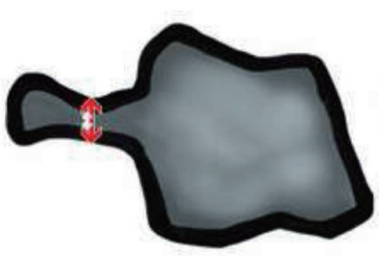

Type 1A

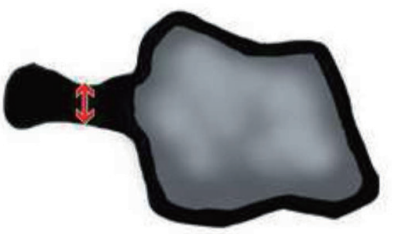

Type 2

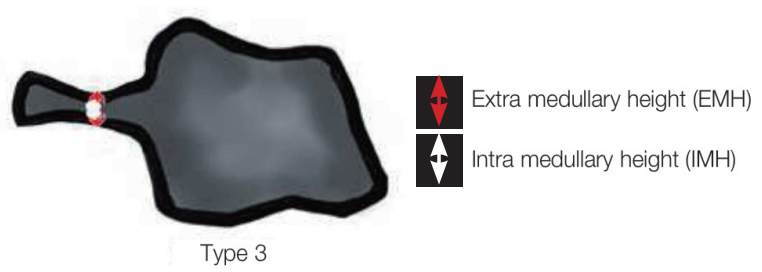

Fig. 4. Pictorial representation of C1 pedicle types. 
pedicles did not significantly differ; consequently, these data were merged.

Average EMH and IMH were $4.48 \pm 0.91$ and $0.86 \pm 0.77$, respectively. Approximately $32 \%$ (27/84) of the pedicles had bone thicknesses of $<4 \mathrm{~mm}, 49 \%$ (41/84) had IMH of $<1 \mathrm{~mm}$, and 38\% (32/84) had no pedicle (no intramedullary canal) (Fig. 3). The average pedicle thickness in women was significantly lesser $(4.21 \pm 0.93 \mathrm{~mm})$ than that in men $(4.73 \pm 0.81 \mathrm{~mm})(p=0.004)$. EMH and IMH were highly correlated $(r=0.93)$.

Here, we propose a radiological classification system (Table 1, Fig. 4) for $\mathrm{C} 1$ pedicles based on observed data and already published literature. The goal of this system is to assist physicians in determining the feasibility of $\mathrm{C} 1$ pedicle screw placement in patients. We classified the pedicles into three main types depending on EMH and IMH (Table 1, Fig. 4). Representative sagittal CT sections are shown in Fig. 5.

This system, as used in the current study, is presented in Table 2 with the pedicle numbers indicating the vari-

Table 2. Pedicle numbers in various types and subtypes of author's classification

$\begin{array}{ll}\begin{array}{l}\text { Radiological classification } \\ \text { of pedicles }\end{array} & \begin{array}{l}\text { No. of pedicles in current } \\ \text { study }\end{array}\end{array}$

Type 1A

42

Type 1B

7

Type 2

8

Type 3 27 ous types and subtypes. $\mathrm{C} 1$ pedicle heights sampled from various ethnic populations are presented in Table 3 [14$16,18,19]$.

\section{Discussion}

Segmental C1-C2 fixation, using atlas lateral masses, was previously described by Goel and Laheri [2]. Since then, the technique is gaining popularity over transarticular fixation as described by Jeanneret and Magerl [20]. However, in order to expose the lateral masses of the atlas, dissection has to be performed around the $\mathrm{C} 2$ nerve, which is surrounded by Batson venous plexus. This dissection
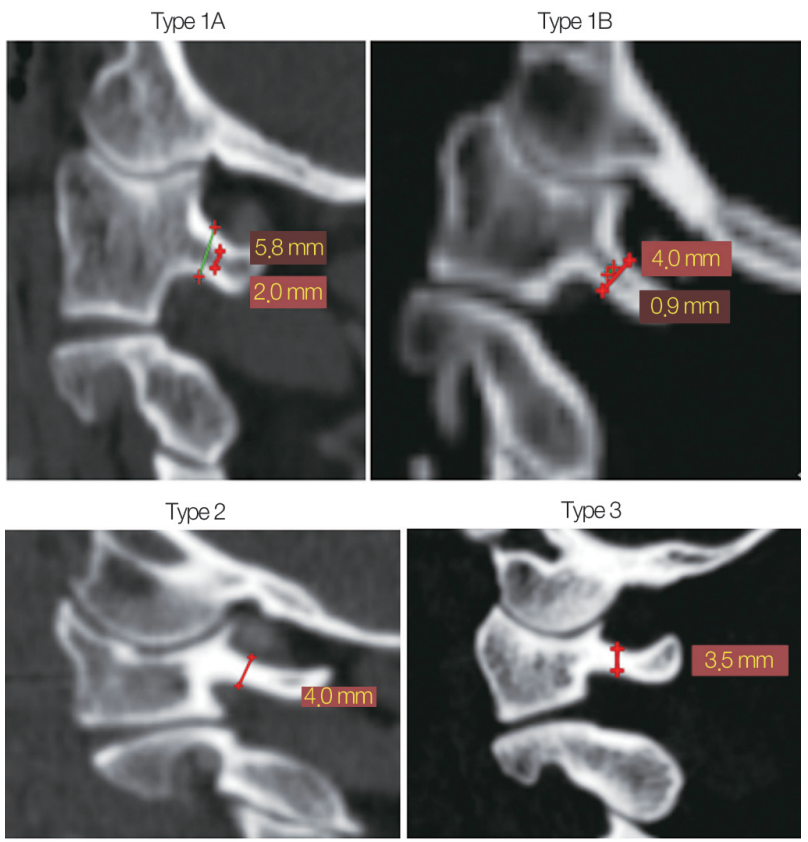

Fig. 5. Representative sagittal scans, depicting $\mathrm{C} 1$ pedicles of various types.

Table 3. C1 pedicle dimensions in various ethnic population

\begin{tabular}{|c|c|c|c|c|c|c|}
\hline Study & Subject & Ethinicity & $\begin{array}{l}\text { No. of } \\
\text { subjects }\end{array}$ & $\begin{array}{l}\text { Measuring } \\
\text { methods }\end{array}$ & $\begin{array}{l}\text { Height of C1 } \\
\text { pedicle }\end{array}$ & $\begin{array}{l}\text { Pedicles } \\
<4 \mathrm{~mm}(\%)\end{array}$ \\
\hline Current study & Patients & Indian & 42 & CT & $4.48 \pm 0.91$ & 32 \\
\hline Qian et al., 2013 [18] & Patients & Oriental & 120 & CT & $4.43 \pm 1.18$ & 23.3 \\
\hline Christensen et al., 2007 [19] & Dried human $\mathrm{C} 1$ specimen & $\begin{array}{l}\text { Western Black and } \\
\text { White Caucasian }\end{array}$ & 120 & Digital callipers & $4.80 \pm 0.93$ & 19.2 \\
\hline Lee et al., 2006 [16] & Dried human $\mathrm{C} 1$ specimen & $\begin{array}{l}\text { Western Black and } \\
\text { White Caucasian }\end{array}$ & 709 & Digital callipers & $3.95 \pm 0.96$ & 53.8 \\
\hline Ma et al., 2005 [15] & Dried human $\mathrm{C} 1$ specimen & $\begin{array}{c}\text { Western Black and } \\
\text { White }\end{array}$ & 50 & Digital calipers & $4.25 \pm 0.51$ & 12 \\
\hline Tan et al., 2003 [14] & Dried human $\mathrm{C} 1$ specimen & Oriental & 50 & Digital calipers & $4.58 \pm 0.65$ & 8 \\
\hline
\end{tabular}

CT, computed tomography. 
often leads to significant bleeding, making visualization of the entry point difficult. Moreover, the purchase obtained with lateral mass screws is primarily cancellous, of short length which is biomechanically a less stable construct than using a pedicle screw. Therefore, bicortical screw insertion is recommended, which puts Internal Carotid artery and Hypoglossal nerve [21] at a significant risk. Lee et al. [16] described a modified technique that included partial burring of the $\mathrm{C} 1 \mathrm{arch}$, thereby reducing bleeding; however, this technique did not address all the shortcomings of lateral mass fixation. Considering these shortcomings, various authors explored screw placement in the $\mathrm{C} 1$ lateral massusing the pedicle, which is usually located just below the lateral aspect of the vertebral artery groove over the $\mathrm{C} 1 \mathrm{arch}$. This allows for longer screw length with good circumferential cortical purchase in the initial third of the trajectory, avoiding the need for dissection around the venous plexus and bicortical screw placement. $\mathrm{C} 1$ pedicle screws are particularly useful in deformity correction surgery or in patients with severe osteoporosis in whom purchase of lateral mass screws may be questionable. However, because of high variations in the $\mathrm{C} 1$ pedicle morphology, preoperative $\mathrm{CT}$ is recommended to identify patients for whom the procedure is unsafe. Some authors have proposed a role of the intramedullary canal in determining the feasibility of $\mathrm{C} 1$ pedicle screw placement.

Despite an initial description of the atlas lateral mass fixation technique in India, studies on Indian patients are lacking. This study presents relevant CT-based $\mathrm{C} 1$ pedicle morphometry to help determine the safety of screw placement in this population.

The mean EMH in our study was $4.48 \mathrm{~mm}$ (standard deviation, \pm 0.91 ), which was higher than that observed in a Chinese CT-based morphometric study done by Qian et al. [18]. The EMH variability in our study was smaller compared with that in their study. A number of cadaver studies, as tabulated in Table 3, have reported wide EMH variance (3.95-4.80 $\mathrm{mm}$ ) among various ethnic groups.

Pedicles with EMH of $<4 \mathrm{~mm}$ are typically considered unsuitable for safe placement of $3.5 \mathrm{~mm}$ screws [22] without splitting the pedicle or injuring the vertebral artery, unless exploration and mobilization of the vertebral artery is done, increasing the operative time and complicating the procedure [23]. Based on this, 32\% of the pedicles in the current study were unsuitable for safe placement, which is significantly higher than that reported in the Chinese study and most Western studies (Table 3). The only study that reported higher percentage of pedicles, with EMH of $<4 \mathrm{~mm}$, was Lee et al. [16]. This study was conducted on a large sample of 709 atlases of African American and Caucasian people.

The intramedullary diameter depicts the cancellous portion of the $\mathrm{C} 1$ pedicle channel. It forms a least resistant path, safely directing the cannulating instrument into the central rigid core of the pedicle, which is resistant to perforation. This reduces superior breaches and reduces the risk of injury to the vertebral artery. In this study, mean IMH was $0.86 \pm 0.77 \mathrm{~mm}$ in an Indian population, which was significantly less than that previously reported in a Chinese population (Table 3). Both the studies by Tan et al. [14] and Qian et al. [18] reported a mean IMH of $>1 \mathrm{~mm}$. In general, al-mm burr/probe is used to create a groove in the pedicle. Consequently, dimensions less than this may impede tract creation by pedicle screws. In our study, $38 \%$ of the patients had cortical pedicles without an intramedullary canal. Some pedicles with EMH of $>4$ $\mathrm{mm}$ also had no intramedullary canals $(9.5 \%$ of the total pedicles). Qian et al. [18] reported similar findings in their CT-based study. This has clinical implications as the drill/probe used to create a channel in cortical bone may slip and lose direction from the central core of the pedicle, injuring the surrounding structures.

EMH and IMH were highly positively correlated $(r=0.93)$. However, as discussed above, pedicle size does not always indicate the presence of an intramedullary canal. There were significant differences between pedicles of males and females. The average thickness in women $(44.21 \pm 0.93 \mathrm{~mm})$ was significantly lesser than that in men $(4.73 \pm 0.81 \mathrm{~mm})$. This observation is in agreement with past studies and may relate to general body habitus differences between the sexes.

The above information, along with published literature (Table 3), guided the development of a system for classifying pedicles based on EMH and IMH. This system may serve as a communication tool to guide the surgeon to preoperatively assess feasibility/difficulties in $\mathrm{C} 1$ pedicle screw placement. Based on this classification system (Table 1, Fig. 1), type 3 pedicles are unsuitable for screw placement and type 2 pedicles require extreme caution as there is no intramedullary canal. Together, these account for almost $41.67 \%$ (35/84) of all pedicles in this small series. Given that nearly half of the patients cannot undergo safe placement of screws, this is an extremely challenging technique. Damaging the vertebral artery has 
grave consequences compared with bleeding from the plexus at the $\mathrm{C} 1-\mathrm{C} 2$ joint that is sometimes encountered while laterally placing C1 mass screws. These findings support consideration of alternatives such as $\mathrm{C} 1$ lateral mass screws, sublaminar wires, and occipital plates. Type 1 pedicles, which constitute nearly $58.33 \%$ (49/84) of the study sample, allow placement of pedicle screws without significant difficulties under appropriate precautions and techniques. Nevertheless, within the type 1 category, the $1 \mathrm{~B}$ type requires more vigilance compared with $1 \mathrm{~A}$ as the likelihood of injury/breach is higher in this type due to a small intramedullary canal.

The limitations of the study include a small, retrospective sample size derived from a limited geographical area. Our findings may therefore not address all regional variations. However, this study gives valuable insight into the anatomy and ethnic variability of the channel used for C1 pedicle screws. Moreover, our classification system requires validation in cadaveric and clinical settings. The measurements were performed by two authors using the PACS software. This may have introduced bias; however, studies using similar methodologies have shown high $\mathrm{k}$ values for correlation [24].

\section{Conclusions}

This study confirms prior observations of wide variability in pedicle dimensions between various ethnic groups. CT C1 morphometric data shows that approximately $40 \%$ of the Indian population may be unsuitable candidates for C1 pedicle screw placement. This justifies the need for proper preoperative CT scans before instrumentation is contemplated in this region. Based on our classification system, type $1 \mathrm{~A}$ pedicles maybe safe for $\mathrm{C} 1$ pedicle screw placement. However, caution is required while contemplating the placement of pedicle screws in Type $1 \mathrm{~B}$ and extreme caution is required for type 2 .

\section{Conflict of Interest}

No potential conflict of interest relevant to this article was reported.

\section{Acknowledgments}

The authors would like to acknowledge the efforts of Ms. Meenakshi Mohan (Research Co-ordinator) for her ad- ministrative support for this study.

\section{References}

1. Elliott RE, Tanweer O, Boah A, et al. Atlantoaxial fusion with transarticular screws: meta-analysis and review of the literature. World Neurosurg 2013;80:62741.

2. Goel A, Laheri V. Plate and screw fixation for atlanto-axial subluxation. Acta Neurochir (Wien) 1994;129:47-53.

3. Harms J, Melcher RP. Posterior C1-C2 fusion with polyaxial screw and rod fixation. Spine (Phila $\mathrm{Pa}$ 1976) 2001;26:2467-71.

4. Goel A, Desai KI, Muzumdar DP. Atlantoaxial fixation using plate and screw method: a report of 160 treated patients. Neurosurgery 2002;51:1351-6.

5. Currier BL, Todd LT, Maus TP, Fisher DR, Yaszemski MJ. Anatomic relationship of the internal carotid artery to the $\mathrm{C} 1$ vertebra: a case report of cervical reconstruction for chordoma and pilot study to assess the risk of screw fixation of the atlas. Spine (Phila Pa 1976) 2003;28:E461-7.

6. Hong JT, Lee SW, Son BC, Sung JH, Kim IS, Park CK. Hypoglossal nerve palsy after posterior screw placement on the C-1 lateral mass: case report. J Neurosurg Spine 2006;5:83-5.

7. Resnick DK, Benzel EC. C1-C2 pedicle screw fixation with rigid cantilever beam construct: case report and technical note. Neurosurgery 2002;50:426-8.

8. Kobayashi Y, Kikuchi S, Konno S, Sekiguchi M. Insertion of lateral mass screw of the atlas via the posterior arch: anatomical study of screw insertion using dry bone samples of the atlas from Japanese cadavers. J Orthop Sci 2008;13:452-5.

9. Dong Y, Hong MX, Jianyi L, Lin MY. Quantitative anatomy of the lateral mass of the atlas. Spine (Phila Pa 1976) 2003;28:860-3.

10. Simsek S, Yigitkanli K, Seckin H, et al. Ideal screw entry point and projection angles for posterior lateral mass fixation of the atlas: an anatomical study. Eur Spine J 2009;18:1321-5.

11. Seal C, Zarro C, Gelb D, Ludwig S. C1 lateral mass anatomy: proper placement of lateral mass screws. J Spinal Disord Tech 2009;22:516-23.

12. Blagg SE, Don AS, Robertson PA. Anatomic determination of optimal entry point and direction for $\mathrm{C} 1$ 
lateral mass screw placement. J Spinal Disord Tech 2009;22:233-9.

13. Gupta S, Goel A. Quantitative anatomy of the lateral masses of the atlas and axis vertebrae. Neurol India 2000;48:120-5.

14. Tan M, Wang H, Wang Y, et al. Morphometric evaluation of screw fixation in atlas via posterior arch and lateral mass. Spine (Phila Pa 1976) 2003;28:888-95.

15. Ma XY, Yin QS, Wu ZH, Xia H, Liu JF, Zhong SZ. Anatomic considerations for the pedicle screw placement in the first cervical vertebra. Spine (Phila Pa 1976) 2005;30:1519-23.

16. Lee MJ, Cassinelli E, Riew KD. The feasibility of inserting atlas lateral mass screws via the posterior arch. Spine (Phila Pa 1976) 2006;31:2798-801.

17. Gebauer M, Barvencik F, Briem D, et al. Evaluation of anatomic landmarks and safe zones for screw placement in the atlas via the posterior arch. Eur Spine J 2010;19:85-90.

18. Qian LX, Hao DJ, He BR, Jiang YH. Morphology of the atlas pedicle revisited: a morphometric CT-based study on 120 patients. Eur Spine J 2013;22:1142-6.

19. Christensen DM, Eastlack RK, Lynch JJ, Yaszemski
MJ, Currier BL. C1 anatomy and dimensions relative to lateral mass screw placement. Spine (Phila Pa 1976) 2007;32:844-8.

20. Jeanneret B, Magerl F. Primary posterior fusion C1/2 in odontoid fractures: indications, technique, and results of transarticular screw fixation. J Spinal Disord 1992;5:464-75.

21. Eck JC, Walker MP, Currier BL, Chen Q, Yaszemski MJ, An KN. Biomechanical comparison of unicortical versus bicortical $\mathrm{C} 1$ lateral mass screw fixation. J Spinal Disord Tech 2007;20:505-8.

22. Bloch O, Holly LT, Park J, Obasi C, Kim K, Johnson JP. Effect of frameless stereotaxy on the accuracy of C1-2 transarticular screw placement. J Neurosurg 2001;95:74-9.

23. Yeom JS, Kafle D, Nguyen NQ, et al. Routine insertion of the lateral mass screw via the posterior arch for $\mathrm{C} 1$ fixation: feasibility and related complications. Spine J 2012;12:476-83.

24. Busscher I, Ploegmakers JJ, Verkerke GJ, Veldhuizen AG. Comparative anatomical dimensions of the complete human and porcine spine. Eur Spine J 2010;19:1104-14. 